\title{
High Concentrations of Presepsin in the Bile and Its Marked Elevation in Biliary Tract Diseases: A Retrospective Analysis
}

Takashi Yamaguchi ${ }^{1}$, Masahiro Ohira ${ }^{1,}$ Naoyuki Kawagoe 1, Shoko Nakamura 1, Shou Tanaka ${ }^{1}$ Rena Oka 1, Yasuhiro Watanabe ${ }^{1}$, Yuta Sato ${ }^{1}$, Atsuhito Saiki 1, Yasuo Matsuzawa 2, Hideaki Bujo ${ }^{3}$, Kensuke Terai ${ }^{4}$, Nobuyuki Hiruta ${ }^{4}$, Ichiro Tatsuno ${ }^{1}$, Chiaki Nakaseko ${ }^{5}$, Hidemasa, Kikuchi ${ }^{6}$, Katsuyoshi Matsuoka ${ }^{6}$, Hiromitsu Yokota ${ }^{7}$ and Naomi Shimizu ${ }^{8 *}$

${ }^{1}$ Center for Diabetes, Metabolism and Endocrinology, Toho University Sakura Medical Center, 2850841 Chiba, Japan; takashi_schecter@sakura.med.toho-u.ac.jpe-mail (T.Y.); 600137om@sakura.med.toho-u.ac.jp (M.O.); naoyuki.kawagoe@med.toho-u.ac.jp (N.K.); shouko.nakamura@med.toho-u.ac.jp (S.N.); shou.tanaka@med.toho-u.ac.jp (S.T.); rena.watanabe@med.toho-u.ac.jp (R.O.); 601055wy@med.toho-u.ac.jp (Y.W.); yutasato@sakura.med.toho-u.ac.jp (Y.S.); atsuhito156@sakura.med.toho-u.ac.jp (A.S.); ichiro.tatsuno@med.toho-u.ac.jp (I.T.)

2 Department of Internal Medicine, Toho University Sakura Medical Center, 2850841 Chiba, Japan; yasuo1123@gmail.com (Y.M.)

3 Department of Clinical-Laboratory and Experimental-Research Medicine, Toho University Sakura Medical Center, 2850841 Chiba, Japan; hideaki.bujo@med.toho-u.ac.jp (H.B.)

4 Department of Surgical Pathology, Toho University Sakura Medical Center, 2850841 Chiba, Japan; terai@sakura.med.toho-u.ac.jp (K.T.); nhr@med.toho-u.ac.jp (N.H.)

5 Department of Hematology, International University of Health and Welfare School of Medicine, 2860124 Chiba, Japan; cnakaseko@iuhw.ac.jp (C.N.)

6 Division of Gastroenterology and Hepatology, Department of Internal Medicine, Toho University Sakura Medical Center, 2850841 Chiba, Japan; hidemasa-k88@sakura.med.toho-u.ac.jp (H.K.); matsuoka@fk2.sonet.ne.jp (K.M.)

7 Clinical Laboratory Program, Education Development Center, Faculty of Science Toho University, 2748510 Chiba, Japan; hiromitsu.yokota@sci.toho-u.ac.jp (H.Y.)

8 Department of Hematology, Toho University Sakura Medical Center, 2850841 Chiba, Japan; naomiscib@umin.ac.jp (N.S.)

* Correspondence: naomis-cib@umin.ac.jp; Tel.: +81-43-462-8811; Fax: +81-43-489-9770 (N.S.)

Abstract: Presepsin is a diagnostic and prognostic biomarker of sepsis; however, elevated presepsin levels have also been documented without sepsis. This study aims to retrospectively analyze the laboratory parameters and Sequential Organ Failure Assessment (SOFA) score affecting presepsin levels in 567 patients. Some patients with elevated presepsin levels exhibited renal dysfunction or elevation of biliary enzymes despite a low SOFA score. The univariate regression analysis revealed a close correlation between presepsin levels and SOFA score, serum creatinine (CRE), blood urea nitrogen, and biliary enzymes. In addition, a multivariate regression analysis revealed that SOFA score, alkaline phosphatase (ALP), and CRE independently affected presepsin levels significantly. The analysis of covariance (ANCOVA) revealed that presepsin levels were significantly higher in patients with hepatobiliary disease. Besides, we found that patients who presented with the dilatation of intra- or extrahepatic bile ducts and the elevation of ALP or total bilirubin exhibited remarkable high presepsin levels in the bile. Furthermore, the presepsin production in the liver's Kupffer cells was established by immunostaining in patients who received surgical liver resection. Overall, this study elucidates that biliary enzymes' elevation affects presepsin levels, presepsin exists in high concentrations in the bile, and is positive in Kupffer cells.

Keywords: presepsin; sepsis; Sequential Organ Failure Assessment (SOFA) score; alkaline phosphatase; bile 


\section{Introduction}

CD14, a 55-kDa glycoprotein, is expressed in macrophages, monocytes, and granulocytes, along with their cell membranes [1]; it serves as a receptor for lipopolysaccharide-binding protein complexes. In addition, CD14 activates a series of signal transduction pathways and inflammatory cascades against microorganisms [1,2]. The glycoprotein exists in both membrane-bound and soluble (sCD14) forms. During inflammation, proteases cleave sCD14 in the blood, creating a truncated subtype, called presepsin [3,4].

Presepsin is an established biomarker of sepsis. To date, numerous studies have reported a correlation between presepsin levels and both sepsis severity and outcomes of patients with sepsis. Thus, presepsin has been considerably explored in patients receiving critical care [5-9]. Presepsin is filtered by the glomerulus, reabsorbed and catabolized within proximal tubular cells; consequently, its levels are high in patients with renal failure [10-12].

Previously, presepsin levels have been reported to be markedly elevated in other diseases without sepsis, including hemophagocytic syndrome (HPS) [13] and acute ST-elevation myocardial infarction (STEMI) [14]. Indeed, we also experienced a case of TAFRO (i.e., thrombocytopenia, anasarca, fever, renal failure or reticulin fibrosis, and organomegaly) syndrome that exhibited a remarkable elevation of presepsin levels without an apparent infectious disease (under submission). This study aims to investigate the clinical laboratory parameters that could affect the plasma presepsin levels for conditions other than renal dysfunction and examine the new mechanisms leading to the elevation of presepsin.

\section{Experimental Section}

\subsection{Study Population and Ethical Statement}

We retrospectively examined 611 consecutive patients who were suspected of some infections and got their plasma presepsin levels measured between January 2017 and April 2018. Of these, we excluded 10 patients who were unable to calculate the Sequential Organ Failure Assessment (SOFA) score. As we analyzed only the results of first blood sampling, 34 patients who had been measured more than once were also excluded. Hence, we enrolled 567 patients in the study. This study protocol was approved by the Institutional Review and Ethics Committee of Sakura Hospital, School of Medicine, Toho University (Chiba, Japan; No. S18036); the study was conducted from July 2018 following the rules of the Declaration of Helsinki of 1975 revised in 2013.

In addition, we enrolled 11 patients with either of the following conditions: a malignant biliary tract or pancreatic tumor or benign biliary tract diseases from October 2018 to August 2019. All patients received bile samples collection for cytological examination by percutaneous transhepatic gallbladder drainage, percutaneous transhepatic gallbladder aspiration, endoscopic retrograde biliary drainage, endoscopic nasobiliary drainage, and percutaneous transhepatic cholangial drainage. The studies mentioned above were conducted in compliance with the principles of the Declaration of Helsinki, then performed with an explanation to patients. Moreover, a website with additional information and including an opt-out option was created for these studies (No. S18059).

\subsection{SOFA Score Calculation}

We used the SOFA score, developed by a group of critical care physicians in December 1994 [15], to assess the severity of organ dysfunctions. SOFA comprises scores from six organ systems, graded from 0 to 4 based on the degree of dysfunction/failure; it scores 1-4 points for each of the six organ systems (respiratory, circulation, renal, neurologic, hepatogenic, and coagulation) [16].

\subsection{Measurement of Presepsin in Plasma}

The plasma presepsin levels were measured immediately after blood sampling using a fully automated PATHFAST Presepsin Assay System (LSI Medience Corporation, Tokyo, Japan), as described previously [4,17]. 


\subsection{Sampling and Measurement of Presepsin in the Bile}

All samples were centrifuged at $1500 \mathrm{rpm}$ for $5 \mathrm{~min}$. The supernatants were immediately frozen and stored at $-80^{\circ} \mathrm{C}$ until use. For measurement, the supernatants were diluted to the appropriate range and measured as stated above.

\subsection{Immunostaining}

We used monoclonal rabbit antibodies directed against CD14 (1:100 dilution; ab183322, Abcam plc, Cambridge, UK) and polyclonal rabbit presepsin antibody ( $1 \mu \mathrm{g} / \mathrm{mL}$; Mochida Pharmaceutical Co., Ltd ,Fujieda, Japan) for immunostaining, as described previously [13]. Antibodies for presepsin were purchased from Mochida Pharmaceutical Co., Ltd (Fujieda, Japan). Sections (3-4 $\mu \mathrm{m}$ thick) of paraffin-embedded surgical specimens were prepared, deparaffinized, and hydrated. The sections were subsequently treated at $95^{\circ} \mathrm{C}$ for $10 \mathrm{~min}$ in citrate buffer $(\mathrm{pH}$ 6) for antigen retrieval. Immunohistochemical reactions were performed with an autostainer (the EnVision ${ }^{\mathrm{TM}}$ FLEX, Dako, Glostrup, Denmark). Endogenous peroxidase activity was blocked by treatment with Envision ${ }^{\mathrm{TM}}$ Flex peroxidase-blocking solution (Dako). After washing with Envision ${ }^{\mathrm{TM}}$ Flex Wash Buffer (Dako), the slides were incubated with monoclonal rabbit CD14 antibody and polyclonal rabbit presepsin antibody at room temperature in a moist chamber for $20 \mathrm{~min}$. After washing, the slides were treated with Envision ${ }^{\mathrm{TM}}$ Flex HRP (Dako) for $20 \mathrm{~min}$, followed by color development in Envision ${ }^{\mathrm{TM}}$ Flex DAB + Chromogen with Substrate Buffer (Dako). Finally, the slides were counterstained with hematoxylin.

\subsection{Statistical Analyses}

In this study, data were presented as means \pm SD. Using both univariate and multivariate analyses, we analyzed the correlation between presepsin levels and other clinical laboratory parameters [i.e., white blood cells (WBC), hemoglobin, platelets, aspartate aminotransferase, alanine aminotransferase, alkaline phosphatase (ALP), gamma-glutamyl transferase $(\gamma-G T)$, lactate dehydrogenase (LDH), total bilirubin (T-BIL), serum creatinine (CRE), blood urea nitrogen (BUN), C-reactive protein (CRP), total protein, and serum albumin]. In addition, differences in plasma presepsin levels among groups were analyzed using the analysis of covariance (ANCOVA), with relevant covariates. All statistical analyses were performed using JMP software version 9.0 (SAS, Cary, NC). We considered $P<0.05$ as statistically significant.

\section{Results}

\subsection{Patients' Characteristics and Clinical Parameters}

Table 1 presents the patients' characteristics and numerous clinical laboratory parameters. We examined 567 patients (345 males and 222 females; mean age: $66.7 \pm 18.0$ years). The presepsin level ranged 6.89-16,837 (median: $707.7 \pm 1549.9$ ) pg/mL. Of note, all samples were within the reference range of the PATHFAST system.

Table 1. Patients' characteristics and clinical parameters.

\begin{tabular}{cccccc}
\hline Clinical condition & $\boldsymbol{n}$ & $\begin{array}{c}\text { Ratio } \\
\mathbf{( \% )}\end{array}$ & Variable & Mean \pm SD \\
\hline Total & 567 & 100 & Age & $($ years $)$ & $66.7 \pm 18.0$ \\
Urological disease & 161 & 28.4 & Gender & $(\mathrm{m} / \mathrm{f})$ & $345 / 222$ \\
Respiratory disease & 121 & 21.3 & WBC & $\left(10^{3} / \mu \mathrm{L}\right)$ & $10.5 \pm 5.5$ \\
Gastrointestinal disease & 84 & 14.8 & Hemoglobin & $(\mathrm{g} / \mathrm{dL})$ & $11.9 \pm 2.4$ \\
$\begin{array}{c}\text { Hepatobiliary and } \\
\text { pancreatic disease }\end{array}$ & 57 & 10.1 & Platelets & $\left(10^{4} / \mu \mathrm{L}\right)$ & $22.6 \pm 11.5$ \\
\hline
\end{tabular}




\begin{tabular}{|c|c|c|c|c|c|}
\hline $\begin{array}{c}\text { Central nervous system } \\
\text { disease }\end{array}$ & 10 & 1.8 & AST & (IU/L) & $61.1 \pm 177.2$ \\
\hline Cardiovascular disease & 7 & 1.2 & ALT & $(\mathrm{IU} / \mathrm{L})$ & $41.2 \pm 99.2$ \\
\hline $\begin{array}{l}\text { Skin and connective tissue } \\
\text { disease }\end{array}$ & 7 & 1.2 & ALP & (IU/L) & $334.6 \pm 363.8$ \\
\hline Musculoskeletal disease & 11 & 1.9 & $\gamma-\mathrm{GT}$ & (IU/L) & $78.1 \pm 131.8$ \\
\hline Hematological disease & 15 & 2.6 & $\mathrm{LDH}$ & (IU/L) & $273.1 \pm 244.0$ \\
\hline Gynecological disease & 12 & 2.1 & T-BIL & $(\mathrm{mg} / \mathrm{dL})$ & $1.1 \pm 2.2$ \\
\hline Autoimmune disease & 26 & 4.6 & CRE & $(\mathrm{mg} / \mathrm{dL})$ & $1.11 \pm 1.26$ \\
\hline \multirow[t]{6}{*}{ Others } & 56 & 9.9 & BUN & $(\mathrm{mg} / \mathrm{dL})$ & $21.7 \pm 18.6$ \\
\hline & & & Total protein & $(\mathrm{g} / \mathrm{dL})$ & $6.8 \pm 0.9$ \\
\hline & & & Serum albumin & $(\mathrm{g} / \mathrm{dL})$ & $3.8 \pm 0.7$ \\
\hline & & & Presepsin & $(\mathrm{pg} / \mathrm{mL})$ & $707.7 \pm 1549.9$ \\
\hline & & & CRP & $(\mathrm{mg} / \mathrm{dL})$ & $9.17 \pm 7.74$ \\
\hline & & & SOFA score & & $2.03 \pm 2.68$ \\
\hline
\end{tabular}

WBC, white blood cells; AST, aspartate aminotransferase; ALT, alanine aminotransferase; ALP, alkaline phosphatase; $\gamma$-GT, gamma-glutamyl transferase; LDH, lactate dehydrogenase; T-BIL, total bilirubin; CRE, serum creatinine; BUN, blood urea nitrogen; CRP, C-reactive protein; SOFA, Sequential Organ Failure Assessment.

\subsection{SOFA Score}

Figure 1 shows the correlation between plasma presepsin levels and SOFA score. The patients' score ranged $0-17$. The patients' number and presepsin level in each group were as follows (SOFA score, $n$, median \pm SD of plasma presepsin): $0,207,190 \pm 280 \mathrm{pg} / \mathrm{mL} ; 1,109,300 \pm 344 \mathrm{pg} / \mathrm{mL} ; 2,89$, $442 \pm 775 \mathrm{pg} / \mathrm{mL} ; 3,46,569 \pm 809 \mathrm{pg} / \mathrm{mL} ; 4,41,502 \pm 1525 \mathrm{pg} / \mathrm{mL} ; 5,25,697 \pm 1060 \mathrm{pg} / \mathrm{mL} ; 6,16,728 \pm$ $1313 \mathrm{pg} / \mathrm{mL} ; 7,6,3417 \pm 4666 \mathrm{pg} / \mathrm{mL} ; 8,7,501 \pm 1419 \mathrm{pg} / \mathrm{mL} ; 9,5,470 \pm 147 \mathrm{pg} / \mathrm{mL} ; 10,5,745 \pm 4819$ $\mathrm{pg} / \mathrm{mL}$. For each SOFA score from 11 to 17 , there were only one or two patients. As shown in Figure 1 , the presepsin level significantly and positively correlated with the SOFA scores $(r=0.525 ; P \leq$ 0.0001); however, several patients exhibited abnormally high presepsin levels even with a low SOFA score.

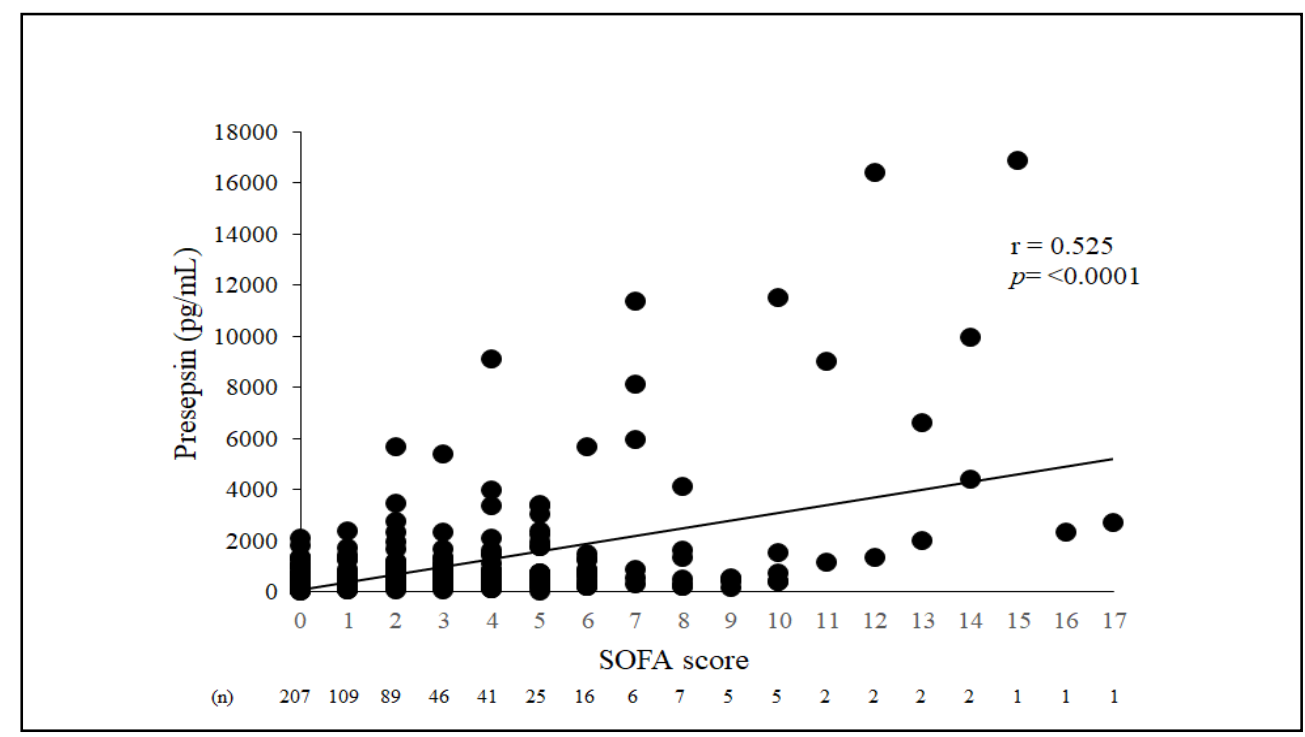

Figure 1. Correlation between presepsin and Sequential Organ Failure Assessment (SOFA) score. 
In addition, we analyzed the clinical and laboratory data in patients who revealed highest presepsin levels in SOFA score from 0 to 5 (SOFA score, disease, plasma presepsin level, ALP, CRE). The data were as follows: 0, acute cholangitis, $2081 \mathrm{pg} / \mathrm{mL}, 2510 \mathrm{IU} / \mathrm{L}, 0.82 \mathrm{mg} / \mathrm{dL} ; 1$, acute cholangitis, $2392 \mathrm{pg} / \mathrm{mL}, 1117 \mathrm{IU} / \mathrm{L}, 1.29 \mathrm{mg} / \mathrm{dL}$; 2, urinary-tract infection, $5665 \mathrm{pg} / \mathrm{mL}, 232 \mathrm{IU} / \mathrm{L}, 1.68 \mathrm{mg} / \mathrm{dL} ; 3$, prostate cancer, $5371 \mathrm{pg} / \mathrm{mL}, 678 \mathrm{IU} / \mathrm{L}, 2.19 \mathrm{mg} / \mathrm{dL} ; 4$, acute hepatitis, $9075 \mathrm{pg} / \mathrm{mL}, 460 \mathrm{IU} / \mathrm{L}, 3.32$ $\mathrm{mg} / \mathrm{dL} ; 5$, chronic renal failure, $3425 \mathrm{pg} / \mathrm{mL}, 306 \mathrm{IU} / \mathrm{L}, 5.27 \mathrm{mg} / \mathrm{dL}$.

\subsection{Correlation between Presepsin Levels in Plasma and Various Parameters}

Univariate regression analysis was performed to analyze the correlation between presepsin levels and several clinical parameters. As shown in Figure 2, presepsin levels significantly and positively correlated with the following parameters: ALP $(r=0.465, P<0.0001$; Figure $2 \mathrm{a}), \gamma$-GT $(r=$ 0.312, $P<0.0001$; Figure 2b), T-BIL $(r=0.385, P<0.0001$; Figure 2c), and CRE $(r=0.594, P<0.0001$; Figure $2 \mathrm{~d})$. Table 2 shows other that parameters positively correlated as follows: SOFA $(r=0.525, P<$ 0.0001); LDH ( $r=0.304, P<0.0001)$; BUN $(r=0.485, P<0.0001)$.

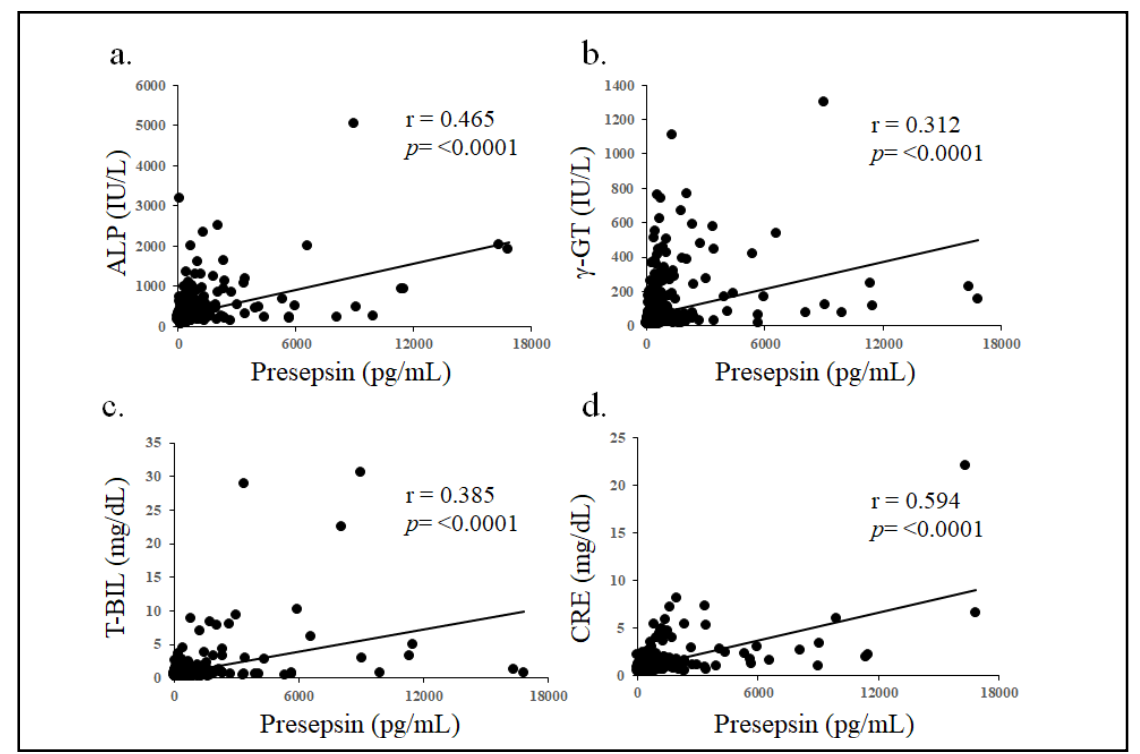

Figure 2. Correlation between presepsin values and alkaline phosphatase (ALP), gamma-glutamyl transferase $(\gamma-G T)$, total bilirubin (T-BIL), and serum creatinine (CRE). Presepsin versus $\gamma$-GT, ALP, T-BIL, and CRE plots (a-d) and linear regressions. [Note: other abbreviations are shown in Table 2.]

In addition, Table 2 summarizes the results of the multivariate regression analysis for the correlation between presepsin and other clinical parameters. As the SOFA score, ALP, LDH, CRE, $\mathrm{CRP}$, and WBC were correlated in the univariate analysis, they were included in the model. Of note, some variables were removed from the regression model because of collinearity with other variables (i.e., $\gamma$-GT and T-BIL were removed because of collinearity with ALP; BUN was removed because of collinearity with CRE). We observed that the SOFA score $(\beta$-coefficient: $0.246498, P<0.0001), \operatorname{ALP}(\beta$ coefficient: $0.359898, P<0.0001)$, and CRE $(\beta$-coefficient: $0.425216, P<0.0001)$ were independent predictors of presepsin levels (Table 2).

Table 2. Univariate and multivariate analysis of correlation with presepsin in all patients $(n=567)$.

\begin{tabular}{lcccccc}
\hline \multicolumn{2}{l}{ Univariate regression analysis } & \multicolumn{4}{c}{ Multivariate regression analysis } \\
\hline Variable & $r$ & $P$ & Variable & $\begin{array}{c}\beta \text {-coefficie } \\
\text { nt }\end{array}$ & SE & $P$ \\
\hline
\end{tabular}




\begin{tabular}{|c|c|c|c|c|c|c|}
\hline Age & 0.078 & 0.0633 & SOFA score & 0.246498 & 20.0653 & $<0.0001$ \\
\hline SOFA & 0.525 & $<0.0001$ & ALP & 0.359898 & 0.12688 & $<0.0001$ \\
\hline AST & 0.128 & 0.0023 & $\mathrm{LDH}$ & -0.03834 & 0.20528 & 0.2362 \\
\hline ALT & 0.167 & $<0.0001$ & CRE & 0.425216 & 42.2233 & $<0.0001$ \\
\hline ALP & 0.465 & $<0.0001$ & CRP & 0.001169 & 5.9836 & 0.9688 \\
\hline$\gamma-\mathrm{GT}$ & 0.312 & $<0.0001$ & WBC & 0.05949 & 0.00844 & 0.0457 \\
\hline LDH & 0.304 & $<0.0001$ & & & & \\
\hline T-BIL & 0.385 & $<0.0001$ & & & & \\
\hline BUN & 0.485 & $<0.0001$ & & & & \\
\hline CRE & 0.594 & $<0.0001$ & & & & \\
\hline Total protein & -0.190 & $<0.0001$ & & & & \\
\hline Serum albumin & -0.252 & $<0.0001$ & & & & \\
\hline CRP & 0.145 & 0.005 & & & & \\
\hline WBC & 0.148 & 0.0004 & & & & \\
\hline Hemoglobin & -0.124 & 0.0031 & & & & \\
\hline Platelets & -0.1 .02 & 0.0155 & & & & \\
\hline
\end{tabular}

WBC, white blood cells; AST, aspartate aminotransferase; ALT, alanine aminotransferase; ALP, alkaline phosphatase; $\gamma$-GT, gamma-glutamyl transferase; LDH, lactate dehydrogenase; T-BIL, total bilirubin; CRE, serum creatinine; BUN, blood urea nitrogen; CRP, C-reactive protein; SOFA, Sequential Organ Failure Assessment; SE; standard error.

Model: $r^{2}=0.546195, P<0.0001$.

\subsection{Comparison of Adjusted Plasma Presepsin Levels among Groups with Various Clinical Conditions}

Figure 3 shows a comparison of adjusted plasma presepsin levels among groups with various clinical conditions. Among all groups, the plasma presepsin level adjusted by the SOFA score and CRE was the highest in the group with hepatobiliary and pancreatic disease $(1497.3 \pm 311.2 \mathrm{pg} / \mathrm{mL})$. A post-hoc analysis revealed significant differences between adjusted plasma presepsin levels with hepatobiliary and pancreatic disease and those with other diseases, except for cardiovascular disease $(912.7 \pm 488.2 \mathrm{pg} / \mathrm{mL})$, skin and connective tissue disease $(1233.5 \pm 630.1 \mathrm{pg} / \mathrm{mL})$, and musculoskeletal disease $(805.4 \pm 218.3 \mathrm{pg} / \mathrm{mL})$.

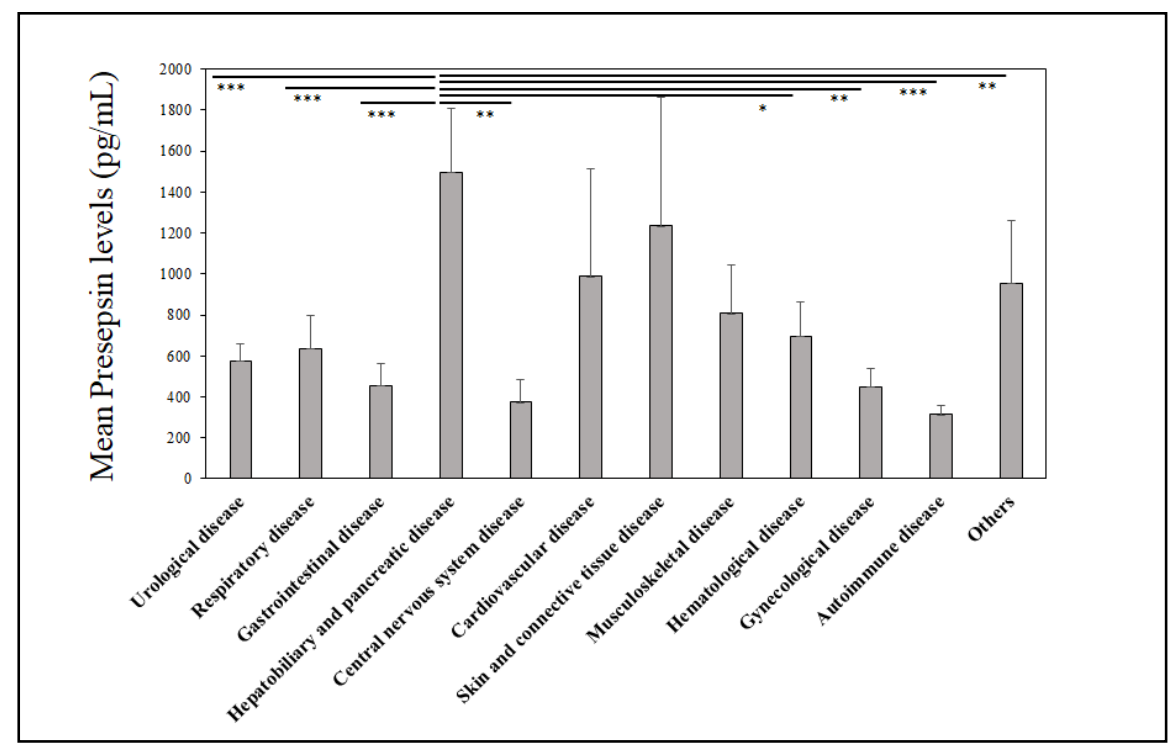

Figure 3. Comparison of adjusted plasma presepsin levels among groups with various clinical conditions. The plasma presepsin level was adjusted by the Sequential Organ Failure Assessment 
(SOFA) score and serum creatinine (CRE). Data are represented as mean \pm standard error (SE). ${ }^{*} \mathrm{P}<$ $0.05,{ }^{* *} \mathrm{P}<0.01,{ }^{* * *} \mathrm{P}<0.001$ : one-way ANOVA followed by the Bonferroni multiple comparison test.

\subsection{Bile Presepsin and Clinical Conditions}

We evaluated bile presepsin levels in 11 patients ( 8 males and 3 females; mean age: $76.0 \pm 9.1$ years) from whom we collected the bile. Table 3 presents the sampling method of bile. Of 11 patients, 8 had biliary tract diseases, 2 had pancreatic cancer, 1 had malignant lymphoma. The presepsin levels in the bile and plasma were $117,610.0 \pm 230,936.9$ and $1495.0 \pm 1919.1 \mathrm{pg} / \mathrm{mL}$, respectively. We observed no correlation between presepsin levels in the bile and plasma because of the time lag of sampling (Table 3). In addition, ALP and T-BIL were measured on the same day of bile sampling. The presepsin levels in the bile revealed an abnormal elevation in almost all patients, excluding Cases 4 and 6 . Of note, Case 3 exhibited the highest level at 638,100 pg/mL.

Moreover, we assessed the dilatation of intra- and extrahepatic bile ducts by abdominal ultrasonography and computed tomography. As shown in Table 3, patients who exhibited the dilatation of intra- or extrahepatic bile ducts and the elevation of ALP or T-BIL levels displayed remarkably high presepsin levels in the bile.

Table 3. Patients' characteristics and clinical data of 11 patients.

\begin{tabular}{|c|c|c|c|c|c|c|c|c|c|}
\hline \multirow[t]{3}{*}{ Case } & \multirow[t]{3}{*}{$\begin{array}{c}\mathrm{Ag} \\
\mathrm{e}\end{array}$} & \multirow[t]{3}{*}{$\begin{array}{l}\text { Se } \\
x\end{array}$} & \multirow[t]{3}{*}{ Disease } & \multicolumn{2}{|c|}{$\begin{array}{c}\text { Presepsin } \\
\text { (pg/mL) }\end{array}$} & \multirow[t]{3}{*}{$\begin{array}{c}\text { Day } \\
*\end{array}$} & \multirow[t]{3}{*}{$\begin{array}{l}\text { Procedu } \\
\text { re }\end{array}$} & \multicolumn{2}{|c|}{$\begin{array}{l}\text { Findings of the bile } \\
\text { duct dilatation and } \\
\text { ALP, T-BIL }\end{array}$} \\
\hline & & & & Bile & plasm & & & Intrahepati & ALP \\
\hline & & & & & $\mathrm{a}$ & & & $\begin{array}{c}\mathrm{c} / \\
\text { extrahepati } \\
\mathrm{c}\end{array}$ & $\begin{array}{l}(\mathrm{IU} / \mathrm{L}) / \\
\mathrm{T}-\mathrm{BIL} \\
(\mathrm{mg} / \mathrm{dL})\end{array}$ \\
\hline 1 & 76 & $\mathrm{M}$ & $\begin{array}{l}\text { Acute gallstone } \\
\text { cholecystitis }\end{array}$ & 2678 & 304 & -1 & PTGBD & $-/-$ & $200 / 1.3$ \\
\hline 2 & 81 & $\mathrm{M}$ & $\begin{array}{c}\text { Acute gallstone } \\
\text { cholecystitis }\end{array}$ & 12,614 & 7407 & -1 & PTGBD & $+/-$ & $793 / 3.1$ \\
\hline 3 & 54 & $\mathrm{M}$ & $\begin{array}{c}\text { Acute } \\
\text { cholangitis }\end{array}$ & $\begin{array}{c}638,10 \\
0\end{array}$ & 1084 & -11 & ERBD & $-/+$ & $401 / 1.2$ \\
\hline 4 & 64 & $\mathrm{~F}$ & $\begin{array}{l}\text { Acute gallstone } \\
\text { cholecystitis }\end{array}$ & 148 & 663 & 0 & PTGBA & $-1-$ & $453 / 1.1$ \\
\hline 5 & 81 & $\mathrm{~F}$ & $\begin{array}{c}\text { Acute common } \\
\text { bile duct stone } \\
\text { and gallstone } \\
\text { cholecystitis }\end{array}$ & 3119 & 512 & -3 & PTGBD & $-1-$ & $147 / 0.9$ \\
\hline 6 & 72 & M & $\begin{array}{c}\text { Acute } \\
\text { cholangitis and } \\
\text { gallstone } \\
\text { cholecystitis }\end{array}$ & 73.6 & 2412 & -2 & ENBD & $-1-$ & $192 / 0.9$ \\
\hline 7 & 79 & $\mathrm{M}$ & $\begin{array}{l}\text { Acute common } \\
\text { bile duct stone } \\
\text { and gallstone } \\
\text { cholecystitis }\end{array}$ & $\begin{array}{c}405,50 \\
0\end{array}$ & 705 & +2 & ERBD & $-/+$ & $374 / 5.2$ \\
\hline 8 & 64 & $\mathrm{M}$ & $\begin{array}{l}\text { Choledocholithia } \\
\text { sis cholangitis }\end{array}$ & $\begin{array}{c}586,30 \\
0\end{array}$ & 1495 & -2 & ENBD & $-/+$ & $614 / 7.2$ \\
\hline 9 & 75 & $\mathrm{M}$ & $\begin{array}{l}\text { Pancreatic head } \\
\text { cancer }\end{array}$ & $\begin{array}{c}139,50 \\
0\end{array}$ & 1575 & -3 & ERBD & $-/+$ & $274 / 0.6$ \\
\hline 10 & 84 & $\mathrm{~F}$ & $\begin{array}{l}\text { Pancreatic head } \\
\text { cancer }\end{array}$ & $\begin{array}{c}117,60 \\
0\end{array}$ & 1831 & -4 & ERBD & $+/-$ & $\begin{array}{c}1743 / 5 \\
9\end{array}$ \\
\hline
\end{tabular}




\begin{tabular}{|c|c|c|c|c|c|c|c|c|c|}
\hline 11 & 83 & $\mathrm{M}$ & $\begin{array}{l}\text { Malignant } \\
\text { lymphoma }\end{array}$ & $\begin{array}{c}223,40 \\
0\end{array}$ & 3147 & 0 & PTCD & $+/+$ & $823 / 3.2$ \\
\hline $\begin{array}{c}\text { Media } \\
\mathrm{n}\end{array}$ & 76 & & & $\begin{array}{c}117,61 \\
0\end{array}$ & 1495 & -2 & & & $401 / 1.3$ \\
\hline SD & 9.1 & & & $\begin{array}{c}230,93 \\
7\end{array}$ & 1919 & 3.0 & & & $438 / 2.2$ \\
\hline
\end{tabular}

PTGBD, percutaneous transhepatic gallbladder drainage; PTGBA, percutaneous transhepatic gallbladder aspiration; ERBD, endoscopic retrograde biliary drainage; ENBD, endoscopic nasobiliary drainage; PTCD, percutaneous transhepatic cholangial drainage.

Day*, Interval between plasma collection and bile collection.

\subsection{Immunostaining of presepsin in the liver}

In this study, 2 patients had their liver tissues examined by immunostaining for CD14 and presepsin. While Case 1 (age: 65 years, male) was operated for metastatic colon cancer in the liver in August 2018, Case 2 (age: 66 years, male) was operated for moderately differentiated hepatocellular carcinoma with a chronic hepatitis B infection in February 2019. As shown in Figure 4, CD14 was positive in Kupffer cells in the sinusoids of the liver's parenchyma without carcinoma invasion, and presepsin was also positive in Kupffer cells.

\section{Case 1}

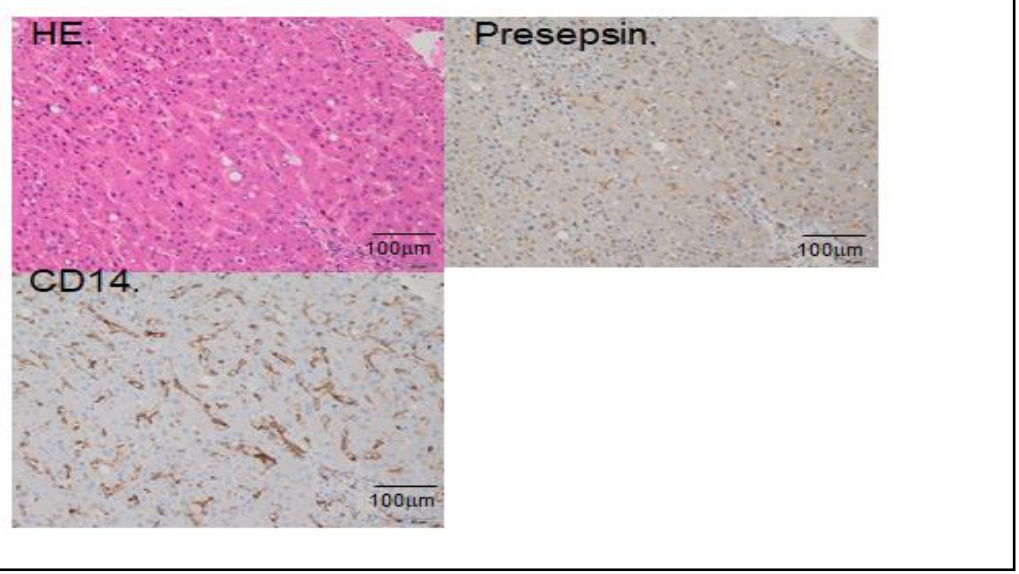




\section{Case 2.}

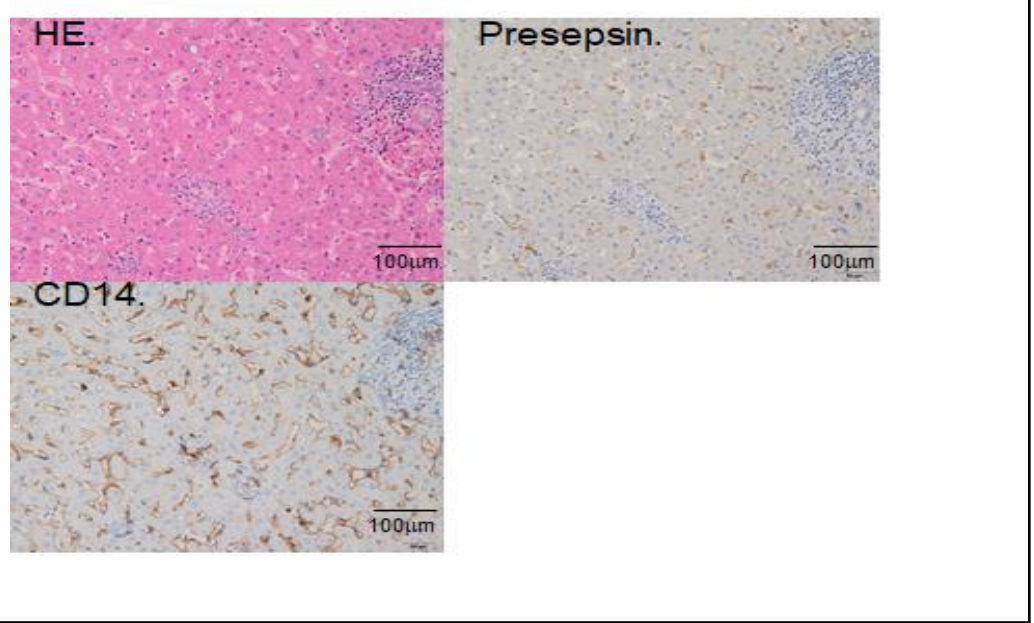

Figure 4. Immunostaining of the liver parenchyma without carcinoma invasion from 2 patients with carcinomas. Hematoxylin-eosin (H\&E), CD14, and presepsin staining in 2 patients. Case 1 presented with metastatic colon cancer in the liver, while Case 2 presented with moderately differentiated hepatocellular carcinoma.

\section{Discussion}

Presepsin is regarded as useful for not only sepsis diagnosis but also as a prognostic predictor [5-9]. Behnes et al. reported that presepsin levels by criteria for the diagnosis of sepsis severity in the intensive care unit treatment were as follows: $\geqq$ sepsis, cutoff: $530 \mathrm{pg} / \mathrm{mL}$; severe sepsis, cutoff: 600 $\mathrm{pg} / \mathrm{mL}$; and $\geqq$ septic shock, cutoff: $700 \mathrm{pg} / \mathrm{mL}$; moreover, presepsin levels exhibited a significant prognostic value for 30 days and 6 months for all-cause mortality [5]. In addition, Liu et al. reported that the median values of presepsin in sepsis, severe sepsis, and septic shock were 325, 787, and 1084 $\mathrm{pg} / \mathrm{mL}$, respectively [8].

Lately, the significance of the SOFA score has increased manifold and it has been incorporated in the latest surviving sepsis campaign as a tool to describe and detect sepsis [18]. In our study, there was no bias of disease state, which is recognized in six organ systems (i.e., respiratory, circulation, renal, neurologic, hepatogenic, and coagulation). As we included many mild infectious patients, the median of the SOFA score was 2.03; however, the median of the plasma presepsin level was as high as $707.7 \mathrm{pg} / \mathrm{mL}$, accompanied by a wide variation. Hence, there is a possibility that independent factors without apparent infection affect the levels of plasma presepsin levels.

Figure 1 shows that patients with high presepsin levels, although with a low SOFA score, and those with renal dysfunction or acute cholecystitis showing ALP elevation revealed a remarkable elevation of plasma presepsin levels. In addition, Table 2 and Figure 2 explain a strong correlation between biliary enzymes and presepsin levels, following univariate regression analysis. Furthermore, presepsin levels strongly correlated with ALP in a multivariate regression analysis (Table 2). Moreover, presepsin levels were significantly higher in hepatobiliary disease in the ANCOVA analysis adjusted by the SOFA score and CRE (Figure 3).

Elefsiniotis et al. reported that plasma presepsin levels were elevated in uncomplicated cirrhotic patients; they demonstrated that patients with decompensated liver disease (DLD) exhibited higher presepsin levels than patients with compensated liver disease (CLD; $441.0 \pm 442.5$ vs. $262.0 \pm 179.0$ $\mathrm{pg} / \mathrm{mL})$. In addition, patients with DLD exhibited higher T-BIL than patients with CLD (3.1 $\pm 4.0 \mathrm{vs.}$ $0.9 \pm 0.9$ ) [19]. Based on these results, our study focused on presepsin levels in the bile. As shown in Table 3, the median level of presepsin in the bile $(117,610 \mathrm{pg} / \mathrm{mL})$ was 100 times higher than plasma presepsin levels $(1495 \mathrm{pg} / \mathrm{mL})$ in 11 patients. Moreover, we noted a tendency that patients with remarkable elevation of presepsin in the bile show the dilatation of intra- or extrahepatic bile ducts and the elevation of ALP or T-BIL. 
$\mathrm{Su}$ et al. reported that CD14 is highly expressed in hepatocytes, similar to macrophages and monocytes [20]. Pan et al. reported that human sCD14 is regulated differently in monocytes and hepatocytes [21]. As presepsin is a truncated N-terminal fragment of CD14 [4], we speculated that the overexpression of CD14 in hepatocytes could affect the elevation of presepsin. Thus, we focused on Kupffer cells, macrophages in the liver, as the cells of presepsin production. Our findings established that presepsin was positive in Kupffer cells (Figure 4). Although the liver tissues of the two cases did not exhibit any dilatation of the bile duct, presepsin expressed predominantly in Kupffer cells. Overall, these findings might suggest that increase of the bile duct pressure results in the presepsin overexpression of Kupffer cells, leading to the elevation of presepsin in the bile and plasma.

Previously, we reported a case of TAFRO syndrome that exhibited a remarkable elevation of presepsin level $(2741 \mathrm{pg} / \mathrm{mL})$ without an apparent infectious disease (under submission). TAFRO syndrome is a systemic inflammatory disorder and considered to be a variant of multicentric Castleman's disease [22,23]. Our case revealed remarkably high presepsin levels, accompanied by the ALP elevation. Likewise, Tokunaga et al. reported that a TAFRO syndrome case revealed elevation of presepsin $(1482 \mathrm{pg} / \mathrm{mL})$ without sepsis [24]. Indeed, to date, several reports have been published regarding the elevation of ALP in TAFRO syndrome [23,25-31]. Furthermore, Nagai et al. reported that liver biopsy exhibited cholangitis in TAFRO syndrome [32].

Arai et al. reported elevated presepsin levels in patients who developed HPS after allogeneic hematopoietic cell transplantation (HCT); besides, they found that patients with higher presepsin levels exhibited inferior overall survival rates, with a median presepsin level on day 28 following HCT $(2786 \mathrm{pg} / \mathrm{mL})$ [13]. Caglar et al. reported that presepsin levels in patients with STEMI were elevated, with a median presepsin level of $1988.89 \mathrm{pg} / \mathrm{mL}$ [14]. As the studies mentioned above did not evaluate multiple organ failure, we surmised that presepsin levels described in these reports could have been affected by both hepatobiliary tract and renal dysfunction.

\section{Conclusions}

This study suggests that presepsin levels increase with the elevation of biliary enzymes in patients without renal dysfunction and sepsis. Furthermore, presepsin exists at high concentrations in the bile with the dilatation of intra- or extrahepatic bile ducts and is positive in Kupffer cells.

Author Contributions: Conceptualization, design, and writing - original draft preparation, N.S; data analysis, T.Y., M.O. and N.S.; critical discussion of the results, N.K., S.N., S.T., R.O., Y.W., Y.S., A.S., Y.M., H.B., K.T., N.H., C.N., I.T., and H.Y. All authors have read and agreed to the published version of the manuscript.

Funding: This research received no external funding.

Acknowledgments: We thank Kamon Shirakawa, Yasuhiro Yanagisawa, and Chika Kawai for measuring presepsin in the plasma and Toru Yamakawa for purchasing the presepsin antibody.

Conflicts of Interest: The authors declare no conflict of interest.

\section{References}

1. Wright, S. D.; Ramos, R. A.; Tobias, P. S.; Ulevitch, R. J.; Mathison, J. C. Cd14, a receptor for complexes of lipopolysaccharide (Lps) and Lps binding protein. Science. 1990, 249, 1431-1433.

2. Zhang, J.; Hu, Z. D.; Song, J.; Shao, J. Diagnostic value of presepsin for sepsis: A systematic review and meta-analysis. Medicine (Baltimore). 2015, 94, 1-8.

3. Mussap, M.; Noto, A.; Fravega, M.; Fanos, V. Soluble Cd14 subtype presepsin (Scd14-St) and lipopolysaccharide binding protein $(\mathrm{Lbp})$ in neonatal sepsis: New clinical and analytical perspectives for two old biomarkers. J. Matern. Fetal. Neonat. Med. 2011, 24 Suppl 2, 12-14.

4. Shirakawa, K.; Naitou, K.; Hirose, J.; Takahashi, T.; Furusako, S. Presepsin (Scd14-St): Development and evaluation of one-step Elisa with a new standard that is similar to the form of presepsin in septic patients. Clin. Chem. Lab. Med. 2011, 49, 937-939. 
5. Behnes, M.; Bertsch, T.; Lepiorz, D.; Lang, S.; Trinkmann, F.; Brueckmann, M.; Borggrefe, M.; Hoffmann, U. Diagnostic and prognostic utility of soluble Cd 14 subtype (presepsin) for severe sepsis and septic shock during the first week of intensive care treatment. Crit. Care. 2014, 18, 507.

6. Shozushima, T.; Takahashi, G.; Matsumoto, N.; Kojika, M.; Okamura, Y.; Endo, S. Usefulness of presepsin (Scd14-St) measurements as a marker for the diagnosis and severity of sepsis that satisfied diagnostic criteria of systemic inflammatory response syndrome. J. Infect. Chemother. 2011, 17, 764-769.

7. Masson, S.; Caironi, P.; Fanizza, C.; Thomae, R.; Bernasconi, R.; Noto, A.; Oggioni, R.; Pasetti, G. S.; Romero, M.; Tognoni, G., et al. Circulating presepsin (soluble Cd14 Subtype) as a Marker of Host Response in Patients with Severe Sepsis or Septic Shock: Data from the multicenter, randomized Albios trial. Intensive Care Med. 2015, 41, 12-20.

8. Liu, B.; Chen, Y. X.; Yin, Q.; Zhao, Y. Z.; Li, C. S. Diagnostic value and prognostic evaluation of presepsin for sepsis in an emergency department. Crit. Care. 2013, 17, R244.

9. Constantinescu, C.; Bodolea, C.; Pasca, S.; Teodorescu, P.; Dima, D.; Rus, I.; Tat, T.; Achimas-Cadariu, P.; Tanase, A.; Tomuleasa, C., et al. Clinical approach to the patient in critical state following immunotherapy and/or stem cell transplantation: Guideline for the on-call physician. J. Clin. Med. 2019, 8.

10. Nagata, T.; Yasuda, Y.; Ando, M.; Abe, T.; Katsuno, T.; Kato, S.; Tsuboi, N.; Matsuo, S.; Maruyama, S. Clinical impact of kidney function on presepsin levels. PLoS One. 2015, 10:e0129159.

11. Takahashi, G.; Shibata, S.; Fukui, Y.; Okamura, Y.; Inoue, Y. Diagnostic accuracy of procalcitonin and presepsin for infectious disease in patients with acute kidney injury. Diagn. Microbiol. Infect. Dis. 2016, 86, 205-210.

12. Chenevier-Gobeaux, C.; Trabattoni, E.; Roelens, M.; Borderie, D.; Claessens, Y. E. Presepsin (Scd14-St) in emergency department: The need for adapted threshold values? Clin. Chim. Acta. 2014, 427, 34-36.

13. Arai, Y.; Mizugishi, K.; Nonomura, K.; Naitoh, K.; Takaori-Kondo, A.; Yamashita, K. Phagocytosis by human monocytes is required for the secretion of presepsin. J. Infect. Chemother. 2015, 21, 564-569.

14. Caglar, F. N. T.; Isiksacan, N.; Biyik, I.; Opan, S.; Cebe, H.; Akturk, I. F. Presepsin (Scd14-St): Could it be a novel marker for the diagnosis of St elevation myocardial infarction? Arch. Med. Sci. Atheroscler. Dis. 2017, 2, e3-e8.

15. Vincent, J. L.; De Mendonca, A.; Cantraine, F.; Moreno, R.; Takala, J.; Suter, P. M.; Sprung, C. L.; Colardyn, F.; Blecher, S. Use of the Sofa score to assess the incidence of organ dysfunction/failure in intensive care units: Results of a multicenter, prospective study. Working Group on "Sepsis-Related Problems" of the European Society of Intensive Care Medicine. Crit. Care Med. 1998, 26, 1793-1800.

16. Vincent, J. L.; Moreno, R.; Takala, J.; Willatts, S.; De Mendonca, A.; Bruining, H.; Reinhart, C. K.; Suter, P. M.; Thijs, L. G. The Sofa (Sepsis-Related Organ Failure Assessment) score to describe organ dysfunction/failure. On behalf of the Working Group on Sepsis-Related Problems of the European Society of Intensive Care Medicine. Intensive Care Med. 1996, 22, 707-710.

17. Okamura, Y.; Yokoi, H. Development of a point-of-care assay system for measurement of presepsin (Scd14St). Clin. Chim. Acta. 2011, 412, 2157-2161.

18. Singer, M.; Deutschman, C. S.; Seymour, C. W.; Shankar-Hari, M.; Annane, D.; Bauer, M. S; Bellomo, R.; Bernard, G. R.; Chiche, J. D.; Coopersmith, C. M., et al. The Third International Consensus Definitions for Sepsis and Septic Shock (Sepsis-3). JAMA. 2016, 315, 801-810.

19. Elefsiniotis, I.; Tsakiris, S. A.; Barla, G.; Tasovasili, A.; Vrachatis, D.; Mavrogiannis, C. Presepsin levels in cirrhotic patients with bacterial infections and/or portal hypertension-related bleeding, presenting with or without acute kidney injury. Ann. Gastroenterol. 2018, 31, 604-612.

20. Su, G. L.; Dorko, K.; Strom, S. C.; Nussler, A. K.; Wang, S. C. Cd14 expression and production by human hepatocytes. J. Hepatol. 1999, 31, 435-442.

21. Pan, Z.; Zhou, L.; Hetherington, C. J.; Zhang, D. E. Hepatocytes contribute to soluble Cd14 production, and Cd14 expression is differentially regulated in hepatocytes and monocytes. J. Biol. Chem. 2000, 275, 3643036435.

22. Masaki, Y.; Kawabata, H.; Takai, K.; Tsukamoto, N.; Fujimoto, S.; Ishigaki, Y.; Kurose, N.; Kojima, M.; Nakamura, S.; Kinoshita, T., et al. Proposed diagnostic criteria, disease severity classification, and treatment strategy for a novel disorder; Tafro syndrome. Rinsho Ketsueki. 2016, 57, 2029-2037.

23. Masaki, Y.; Nakajima, A.; Iwao, H.; Kurose, N.; Sato, T.; Nakamura, T.; Miki, M.; Sakai, T.; Kawanami, T.; Sawaki, T., et al. Japanese variant of multicentric Castleman's disease associated with serositis and 
thrombocytopenia--a report of two cases: Is Tafro syndrome (Castleman-Kojima Disease) a distinct clinicopathological entity? J. Clin. Exp. Hematop. 2013, 53, 79-85.

24. Tokunaga, M.; Yamada, M.; Yoshikawa, S.; Kondo, A.; Mishima, M.; Inoue, S.; Morita, T.; Tominaga, N. Systemic lupus erythematosus with marked eosinophilia and clinical features mimicking Tafro syndrome. Rinsho Ketsueki. 2018, 59, 688-694.

25. Yamaga, Y.; Tokuyama, K.; Kato, T.; Yamada, R.; Murayama, M.; Ikeda, T.; Yamakita, N.; Kunieda, T. Successful treatment with cyclosporin A in tocilizumab-resistant Tafro syndrome. Intern. Med. 2016, 55, 185-190.

26. Coutier, F.; Meaux Ruault, N.; Crepin, T.; Bouiller, K.; Gil, H.; Humbert, S.; Bedgedjian, I.; Magy-Bertrand, $\mathrm{N}$. A comparison of Tafro syndrome between Japanese and non-Japanese cases: A case report and literature review. Ann. Hematol. 2018, 97, 401-407.

27. Tatekawa, S.; Umemura, K.; Fukuyama, R.; Kohno, A.; Taniwaki, M.; Kuroda, J.; Morishita, Y. Thalidomide for tocilizumab-resistant ascites with Tafro syndrome. Clin. Case Rep. 2015, 3, 472-478.

28. Konishi, Y.; Takahashi, S.; Nishi, K.; Sakamaki, T.; Mitani, S.; Kaneko, H.; Mizutani, C.; Ukyo, N.; Hirata, H.; Tsudo, M. Successful treatment of Tafro syndrome, a variant of multicentric Castleman's disease, with cyclosporine A: Possible pathogenetic contribution of interleukin-2. Tohoku J. Exp. Med. 2015, 236, 289-295.

29. Louis, C.; Vijgen, S.; Samii, K.; Chalandon, Y.; Terriou, L.; Launay, D.; Fajgenbaum, D. C.; Seebach, J. D.; Muller, Y. D. Tafro syndrome in caucasians: A case report and review of the literature. Front Med (Lausanne). 2017, 4, 149.

30. Fujiki, T.; Hirasawa, S.; Watanabe, S.; Iwamoto, S.; Ando, R. Successful treatment by tocilizumab without steroid in a very severe case of Tafro syndrome. CEN Case Rep. 2017, 6, 105-110.

31. Kikuchi, T.; Shimizu, T.; Toyama, T.; Abe, R.; Okamoto, S. Successful treatment of Tafro syndrome with tocilizumab, prednisone, and cyclophosphamide. Intern. Med. 2017, 56, 2205-2211.

32. Nagai, Y.; Ando, S.; Honda, N.; Noguchi, H.; Maemori, M.; Hayashi, T.; Sakai, H. Tafro syndrome showing cholangitis on liver biopsy. Rinsho Ketsueki. 2016, 57, 2490-2495.

(C) 2020 by the authors. Submitted for possible open access publication under the terms and conditions of the Creative Commons Attribution (CC BY) license (http://creativecommons.org/licenses/by/4.0/). 